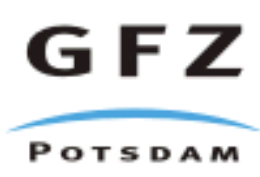

Originally published as:

Kim, W. Y., Wahlström, R., Uski, M. (1989): Regional spectral scaling relations of source parameters for earthquakes in the Baltic shield. - Tectonophysics, 166, 1-3, 151-161 


\title{
Regional spectral scaling relations of source parameters for earthquakes in the Baltic Shield
}

\author{
W.-Y. KIM ${ }^{1}$, R. WAHLSTRÖM ${ }^{1}$ and M. USKI ${ }^{2}$ \\ 'Seismological Department, Uppsala University, Uppsala (Sweden) \\ ${ }^{2}$ Institute of Seismology, University of Helsinki, Helsinki (Finland)
}

(Received December 1, 1987; accepted July 7, 1988)

\begin{abstract}
Kim, W.-Y., Wahlström, R. and Uski, M., 1989. Regional spectral scaling relations of source parameters for earthquakes in the Baltic Shield. In: D. Denham (Editor), Quantification of Earthquakes and the Determination of Source Parameters. Tectonophysics, 166: 151-161.

Spectral analysis of regionally recorded $\mathrm{Lg}$ waves is performed to determine source parameters such as seismic moment, source radius and stress drop of earthquakes in the Baltic Shield, and to derive regional spectral scaling relations. The data consist of about $350 \mathrm{Lg}$ phases on short-period, vertical-component analog seismograms from earthquakes with magnitude $\left(M_{\mathrm{L}}\right)$ ranging from 2 to 5.2. Source radii estimated from the corner frequency show only a slight increase with increasing seismic moment in the range $3 \times 10^{18}$ to $5 \times 10^{20} \mathrm{dyn} \mathrm{cm}$, while the increase is more rapid for larger events. Baltic Shield earthquakes show increasing stress drops, ranging from about 0.1 to 10 bars, for increasing seismic moment. The relatively low stress drops could, in part, be explained by bias due to band-limited analog data.

The slope of the curve relating seismic moment to corner frequency is steeper than -3 , which suggests a departure from a constant stress drop scaling relation proposed for large earthquakes. The derived relationship between the seismic moment $\left(M_{0}\right)$ and magnitude $\left(M_{\mathrm{L}}\right)$ is: $\log M_{0}=16.93+1.01 M_{\mathrm{L}}$ (for $2 \leqslant M_{\mathrm{L}} \leqslant 5.2$ ).
\end{abstract}

\section{Introduction}

In the Baltic Shield, which extends from the Caledonian Mountains in the west to the northwestern U.S.S.R. in the east, the current seismicity is relatively low. Nearly all instrumentally recorded earthquakes are smaller than magnitude 4 $\left(M_{\mathrm{L}}\right)$. So far, only a few studies have been performed to determine dynamic source parameters and focal mechanisms (see, e.g., Slunga, 1979; Bungum et al., 1982; Kulhánek et al., 1983; Slunga et al., 1984; Kim et al., 1985).

Recent studies on the excitation and propagation of regional crustal phases have demonstrated that the Lg-wave amplitude spectrum can be used to determine seismic source parameters such as seismic moment and stress drop (Herrmann and Kijko, 1983; Campillo et al., 1984). The similarity for small earthquakes between the amplitude spectrum of $\mathrm{Lg}$ waves, and that of shear waves predicted by Brune's (1970) source model, has been used by Street et al. (1975) and Hasegawa (1983).

The main purpose of the present study is to quantify source parameters of earthquakes in the Baltic Shield and to derive empirical relationships between the source parameters. Attempts have been made to establish spectral scaling relations for earthquakes in the shield, and to compare them with those for other tectonically similar regions, such as eastern Canada and the eastern United States. 
TABLE 1

Earthquake data

\begin{tabular}{|c|c|c|c|c|c|c|c|c|c|}
\hline \multirow[t]{2}{*}{ Date } & \multicolumn{3}{|c|}{ Origin time } & \multicolumn{2}{|c|}{ Epicenter } & \multirow{2}{*}{$\begin{array}{l}\text { Magnitude } \\
M_{\mathrm{L}}\end{array}$} & \multirow[t]{2}{*}{$M_{0}{ }^{a}$} & \multirow[t]{2}{*}{$f_{0}{ }^{a}$} & \multirow[t]{2}{*}{ No. obs. } \\
\hline & $\mathrm{h}$ & $\mathrm{m}$ & $\mathrm{s}$ & $\left({ }^{\circ} \mathrm{N}\right)$ & $\left({ }^{\circ} \mathrm{E}\right)$ & & & & \\
\hline 28 Sept. 1962 & 17 & 22 & 1 & 64.5 & 20.5 & 4.0 & $8.3 \mathrm{E} 20$ & 2.3 & 4 \\
\hline 1 Aug. 1963 & 16 & 2 & 10 & 62.6 & 27.9 & 3.7 & $3.4 \mathrm{E} 20$ & 3.2 & 6 \\
\hline 3 Oct. 1963 & 2 & 5 & 32 & 64.7 & 23.0 & 3.2 & $1.5 \mathrm{E} 20$ & 2.9 & 6 \\
\hline 23 Jan. 1965 & 11 & 9 & 39 & 65.0 & 23.2 & 3.3 & $2.6 \mathrm{~F} 20$ & 3.1 & 7 \\
\hline 20 Mar. 1965 & 2 & 44 & 54 & 67.4 & 25.9 & 3.5 & $1.4 \mathrm{E} 20$ & 3.5 & 7 \\
\hline 22 Jan. 1966 & 23 & 46 & 47 & 66.7 & 32.4 & 3.6 & 2.2E 20 & 3.4 & 9 \\
\hline 22 June 1966 & 0 & 50 & 38 & 66.9 & 18.8 & 2.2 & 2.2E19 & 3.6 & 2 \\
\hline 14 Oct. 1966 & 16 & 8 & 25 & 65.2 & 22.6 & 2.7 & $3.3 \mathrm{E} 19$ & 3.9 & 2 \\
\hline 4 Jan. 1967 & 4 & 44 & 18 & 67.9 & 21.0 & 3.2 & $1.4 \mathrm{E} 20$ & 2.9 & 3 \\
\hline 4 Feb. 1967 & 15 & 34 & 56 & 59.5 & 13.3 & 3.7 & $3.8 \mathrm{E} 20$ & 3.8 & 4 \\
\hline 13 Apr. 1967 & 8 & 46 & 19 & 68.1 & 20.8 & 3.7 & $2.8 \mathrm{E} 20$ & 3.5 & 6 \\
\hline 13 Apr. 1967 & 9 & 3 & 48 & 63.2 & 18.9 & 3.6 & $5.3 \mathrm{E} 20$ & 2.5 & 7 \\
\hline 20 May 1967 & 23 & 18 & 12 & 66.4 & 33.4 & 5.2 & $1.6 \mathrm{E} 22$ & 1.6 & 2 \\
\hline 29 Nov. 1967 & 9 & 25 & 27 & 60.6 & 17.7 & 3.0 & $5.0 \mathrm{E} 19$ & 3.5 & 1 \\
\hline I June 1968 & 20 & 29 & 59 & 63.4 & 21.2 & 2.6 & $1.8 \mathrm{E} 19$ & 3.8 & 4 \\
\hline 2 Scpt. 1968 & 21 & 34 & 40 & 66.9 & 23.9 & 2.2 & $1.7 \mathrm{E} 19$ & 4.0 & 1 \\
\hline 4 Sept. 1968 & 17 & 9 & 14 & 66.9 & 23.8 & 3.4 & $5.2 \mathrm{E} 20$ & 2.2 & 3 \\
\hline 24 Oct. 1968 & 20 & 13 & 51 & 69.1 & 32.7 & 3.6 & $4.0 \mathrm{E} 20$ & 3.1 & 7 \\
\hline 13 Feb. 1969 & 18 & 4 & 5 & 59.4 & 13.1 & 2.7 & 7.2E19 & 4.1 & 2 \\
\hline 15 Feb. 1969 & 4 & 31 & 21 & 65.3 & 22.9 & 2.1 & $3.6 \mathrm{E} 18$ & 5.9 & 1 \\
\hline 23 May 1969 & 18 & 40 & 25 & 66.0 & 27.2 & 3.3 & $2.3 \mathrm{E} 20$ & 3.1 & 6 \\
\hline 20 July 1969 & 7 & 0 & 53 & 67.0 & 22.9 & 2.8 & $4.1 \mathrm{E} 19$ & 3.8 & 4 \\
\hline 6 Mar. 1970 & 12 & 4 & 23 & 65.0 & 27.5 & 2.3 & $1.7 \mathrm{E} 19$ & 5.8 & 1 \\
\hline 12 May 1970 & 14 & 14 & 13 & 61.0 & 12.8 & 3.2 & $1.6 \mathrm{E} 20$ & 3.0 & 6 \\
\hline 14 June 1970 & 15 & 38 & 13 & 62.0 & 17.5 & 2.0 & $1.6 \mathrm{E} 19$ & 3.0 & 3 \\
\hline 12 Aug. 1970 & 19 & 28 & 46 & 61.5 & 16.4 & 3.0 & 7.0E19 & 3.7 & 4 \\
\hline 24 Feb. 1971 & 9 & 6 & 10 & 62.3 & 27.1 & 2.1 & $9.3 \mathrm{E} 18$ & 4.3 & 1 \\
\hline 10 July 1971 & 4 & 12 & 13 & 58.3 & 13.2 & 2.5 & $7.4 \mathrm{E} 19$ & 3.2 & 2 \\
\hline 28 July 1971 & 23 & 24 & 54 & 62.1 & 17.3 & 3.1 & 7.1E19 & 3.4 & 5 \\
\hline 10 Oct 1971 & 5 & 29 & 6 & 61.9 & 21.9 & 2.5 & $3.6 \mathrm{E} 19$ & 4.9 & 2 \\
\hline 12 June 1972 & 4 & 31 & 33 & 60.1 & 14.5 & 2.8 & $5.3 \mathrm{E} 19$ & 3.6 & 4 \\
\hline 2 Oct. 1972 & 19 & 46 & 5 & 68.3 & 24.2 & 2.0 & $9.5 \mathrm{E} 18$ & 6.4 & 1 \\
\hline 16 Dec. 1972 & 10 & 9 & 27 & 63.5 & 19.7 & 2.8 & $4.1 \mathrm{E} 19$ & 3.8 & 6 \\
\hline 7 Jan. 1973 & 16 & 35 & 11 & 66.9 & 31.4 & 3.7 & $3.1 \mathrm{E} 20$ & 3.2 & 10 \\
\hline 11 Apr. 1973 & 5 & 1 & 37 & 58.8 & 13.4 & 3.9 & $5.1 \mathrm{E} 20$ & 2.3 & 3 \\
\hline 17 Apr. 1973 & 6 & 17 & 59 & 67.9 & 20.0 & 3.3 & $2.7 \mathrm{E} 20$ & 2.9 & 2 \\
\hline 10 Sept. 1973 & 21 & 41 & 9 & 65.7 & 28.8 & 2.7 & 4.1E19 & 4.8 & 1 \\
\hline 26 Nov. 1973 & 21 & 45 & 38 & 62.9 & 18.5 & 3.2 & $1.0 \mathrm{E} 20$ & 3.1 & 4 \\
\hline 10 Dec. 1973 & 20 & 3 & 50 & 66.6 & 25.9 & 3.6 & $2.6 \mathrm{E} 20$ & 3.5 & 10 \\
\hline 10 Dec. 1973 & 20 & 7 & 56 & 66.6 & 25.7 & 2.9 & $1.2 \mathrm{E} 20$ & 3.0 & 4 \\
\hline 5 Feb. 1974 & 22 & 33 & 59 & 58.1 & 14.0 & 2.4 & $3.4 \mathrm{E} 19$ & 3.7 & 2 \\
\hline 21 May 1974 & 16 & 51 & 21 & 58.3 & 12.8 & 3.4 & $2.8 \mathrm{~F} .20$ & 3.1 & 7 \\
\hline 4 June 1974 & 23 & 13 & 51 & 62.3 & 17.2 & 3.6 & $3.2 \mathrm{E} 20$ & 3.2 & 11 \\
\hline 21 June 1974 & 6 & 31 & 8 & 66.0 & 27.3 & 3.6 & $3.4 \mathrm{E} 20$ & 3.2 & 11 \\
\hline 11 Aug. 1975 & 18 & 28 & 9 & 67.5 & 22.5 & 3.9 & $5.3 \mathrm{E} 20$ & 2.5 & 7 \\
\hline 12 Mar. 1976 & 23 & 22 & 21 & 61.2 & 17.0 & 3.3 & $1.5 \mathrm{E} 20$ & 3.3 & 8 \\
\hline 30 Apr. 1976 & 12 & 53 & 53 & 64.4 & 21.1 & 3.1 & $1.0 \mathrm{E} 20$ & 3.0 & 8 \\
\hline 12 July 1976 & 3 & 29 & 50 & 62.8 & 18.2 & 2.2 & $1.8 \mathrm{E} 19$ & 3.9 & 1 \\
\hline 17 Aug. 1976 & 5 & 35 & 54 & 62.9 & 17.8 & 3.5 & $1.8 \mathrm{E} 20$ & 3.1 & 10 \\
\hline 3 Sept. 1976 & 4 & 28 & 0 & 58.4 & 13.9 & 3.7 & $5.1 \mathrm{E} 20$ & 2.4 & 5 \\
\hline 3 Oct. 1976 & 7 & 26 & 57 & 67.8 & 27.4 & 2.6 & $1.7 \mathrm{E} 19$ & 4.2 & 1 \\
\hline
\end{tabular}


TABLE 1 (continued)

\begin{tabular}{|c|c|c|c|c|c|c|c|c|c|}
\hline \multirow[t]{2}{*}{ Date } & \multicolumn{3}{|c|}{ Origin time } & \multicolumn{2}{|c|}{ Epicenter } & \multirow{2}{*}{$\begin{array}{l}\text { Magnitude } \\
M_{\mathrm{L}}\end{array}$} & \multirow[t]{2}{*}{$M_{0}^{a}$} & \multirow[t]{2}{*}{$f_{0}{ }^{\mathbf{a}}$} & \multirow[t]{2}{*}{ No. obs } \\
\hline & $\mathbf{h}$ & $\mathrm{m}$ & s & $\left({ }^{\circ} \mathrm{N}\right)$ & $\left({ }^{\circ} \mathrm{E}\right)$ & & & & \\
\hline 25 Oct. 1976 & 8 & 39 & 45 & 59.3 & 23.3 & 4.9 & $2.3 \mathrm{E} 22$ & 1.3 & 3 \\
\hline 14 Oct. 1977 & 3 & 41 & 49 & 67.0 & 23.4 & 2.9 & 4.9E19 & 3.8 & 2 \\
\hline 7 Nov. 1977 & 0 & 34 & 32 & 68.8 & 27.5 & 3.5 & $3.0 \mathrm{E} 20$ & 3.4 & 8 \\
\hline 2 July 1978 & 17 & 48 & 30 & 64.0 & 20.8 & 2.5 & 4.1E19 & 3.6 & 1 \\
\hline 17 Aug. 1978 & 13 & 2 & 44 & 69.2 & 26.8 & 2.4 & 2.1E19 & 4.6 & 2 \\
\hline 14 Dec. 1978 & 14 & 24 & 48 & 63.7 & 21.1 & 2.9 & $5.8 \mathrm{E} 19$ & 3.8 & 3 \\
\hline 17 Feb. 1979 & 17 & 31 & 22 & 63.2 & 23.9 & 3.8 & $7.3 \mathrm{E} 20$ & 2.1 & 6 \\
\hline 17 Feb. 1979 & 17 & 40 & 58 & 63.2 & 23.9 & 2.6 & 4.5E19 & 4.5 & 4 \\
\hline 11 Nov. 1979 & 23 & 58 & 14 & 61.1 & 16.9 & 2.4 & $3.8 \mathrm{E} 19$ & 4.4 & 1 \\
\hline 23 Dec. 1979 & 14 & 9 & 13 & 59.6 & 18.7 & 3.1 & $7.5 \mathrm{E} 19$ & 4.2 & 2 \\
\hline 28 May 1980 & 10 & 36 & 45 & 67.7 & 24.5 & 3.1 & $1.1 \mathrm{E} 20$ & 2.7 & 4 \\
\hline 29 July 1980 & 9 & 32 & 22 & 68.6 & 23.6 & 2.5 & 3.3E19 & 4.0 & 4 \\
\hline 19 Aug. 1980 & 1 & 13 & 17 & 61.5 & 16.2 & 2.2 & $1.7 \mathrm{E} 19$ & 3.8 & 1 \\
\hline 13 Sept. 1980 & 7 & 59 & 57 & 64.6 & 20.7 & 2.6 & $2.3 \mathrm{E} 19$ & 3.7 & 4 \\
\hline 23 Oct. 1980 & 10 & 55 & 50 & 65.8 & 21.7 & 2.3 & $2.1 \mathrm{E} 19$ & 3.8 & 1 \\
\hline 25 Oct. 1980 & 16 & 45 & 0 & 64.4 & 24.8 & 2.3 & $1.3 \mathrm{E} 19$ & 5.4 & 2 \\
\hline 28 Nov. 1980 & 0 & 1 & 33 & 64.8 & 29.2 & 2.2 & $1.1 \mathrm{E} 19$ & 4.4 & 1 \\
\hline 5 Mar. 1981 & 7 & 20 & 33 & 66.9 & 24.2 & 2.4 & $2.2 \mathrm{E} 19$ & 4.0 & 2 \\
\hline 10 Apr. 1981 & 19 & 43 & 36 & 68.8 & 36.1 & 4.5 & $6.0 \mathrm{E} 21$ & 1.4 & 7 \\
\hline 2 June 1981 & 4 & 47 & 27 & 67.7 & 23.3 & 2.1 & 4.9E19 & 3.2 & 1 \\
\hline 4 July 1981 & 9 & 47 & 52 & 65.0 & 21.0 & 2.8 & $3.9 \mathrm{E} 19$ & 3.9 & 6 \\
\hline 10 July 1981 & 15 & 10 & 11 & 63.6 & 16.7 & 2.5 & $3.9 \mathrm{E} 19$ & 4.0 & 3 \\
\hline 17 Aug. 1981 & 13 & 9 & 17 & 67.5 & 21.9 & 2.6 & $3.4 \mathrm{E} 19$ & 3.4 & 2 \\
\hline 11 Nov. 1981 & 2 & 48 & 52 & 57.1 & 13.1 & 2.9 & $5.2 \mathrm{E} 19$ & 3.2 & 1 \\
\hline 3 Feb. 1982 & 7 & 8 & 43 & 67.3 & 24.0 & 2.7 & $2.9 \mathrm{E} 19$ & 4.0 & 2 \\
\hline 7 May 1982 & 11 & 37 & 32 & 65.5 & 21.3 & 2.1 & $5.6 \mathrm{E} 18$ & 4.9 & 1 \\
\hline 23 June 1982 & 1 & 43 & 28 & 66.1 & 28.3 & 2.1 & $2.0 \mathrm{E} 19$ & 5.5 & 1 \\
\hline 21 July 1982 & 4 & 59 & 47 & 60.9 & 26.2 & 2.9 & 7.9E19 & 3.9 & 3 \\
\hline 8 Oct. 1982 & 5 & 28 & 56 & 64.5 & 20.7 & 2.9 & $6.2 \mathrm{E} 19$ & 4.1 & 5 \\
\hline 18 Aug. 1983 & 6 & 6 & 8 & 65.5 & 21.8 & 2.4 & $3.2 \mathrm{E} 19$ & 5.2 & 1 \\
\hline 29 Sept. 1983 & 5 & 3 & 25 & 63.8 & 17.5 & 4.1 & 2.3E21 & 1.8 & 10 \\
\hline 10 Jan. 1984 & 11 & 16 & 23 & 65.5 & 22.6 & 2.2 & $8.9 \mathrm{E} 18$ & 2.6 & 1 \\
\hline 14 May 1984 & 8 & 31 & 2 & 65.9 & 28.5 & 2.5 & $2.6 \mathrm{E} 19$ & 4.1 & 1 \\
\hline 25 May 1984 & 13 & 18 & 1 & 65.9 & 28.5 & 3.2 & $2.0 \pm 20$ & 3.2 & 5 \\
\hline 3 Aug. 1984 & 22 & 42 & 9 & 65.9 & 28.5 & 2.8 & $6.2 \mathrm{E} 19$ & 3.6 & 4 \\
\hline 25 Aug. 1984 & 19 & 39 & 14 & 67.9 & 19.5 & 3.1 & $1.1 \mathrm{E} 20$ & 3.7 & 4 \\
\hline 24 Dec. 1984 & 8 & 2 & 26 & 66.0 & 28.6 & 2.2 & $2.5 \mathrm{E} 19$ & 4.0 & 1 \\
\hline 8 Jan. 1985 & 1 & 50 & 33 & 64.8 & 20.1 & 3.0 & $8.4 \mathrm{E} 19$ & 2.9 & 4 \\
\hline 14 July 1986 & 14 & 45 & 32 & 58.5 & 14.0 & 3.4 & $2.1 \mathrm{E} 20$ & 3.7 & 4 \\
\hline
\end{tabular}

${ }^{\mathrm{a}} \boldsymbol{M}_{0}$ denotes seismic moment (dyn $\mathrm{cm}$ ) and $f_{0}$ source-spectrum corner frequency $(\mathrm{Hz})$.

\section{Data}

Ninety earthquakes in the Baltic Shield, occurring between 1962 and 1986, were selected for analysis (Fig. 1). The magnitude $\left(M_{\mathrm{L}}\right)$ of these events is between 2 and 5.2. All events with magnitude greater than 3.5 and occurring between 1962 and 1983 were included, whereas for smaller events $\left(M_{\mathrm{L}}<3.5\right)$, a representative selection was made based on magnitude and location. Event data are given in Table 1. All earthquakes are confined to the crust, but more exact focal depths cannot usually be determined.

About $350 \mathrm{Lg}$ waves recorded on short-period, vertical-component analog seismograms from 23 stations in Fennoscandia were used (Fig. 1). Epi- 


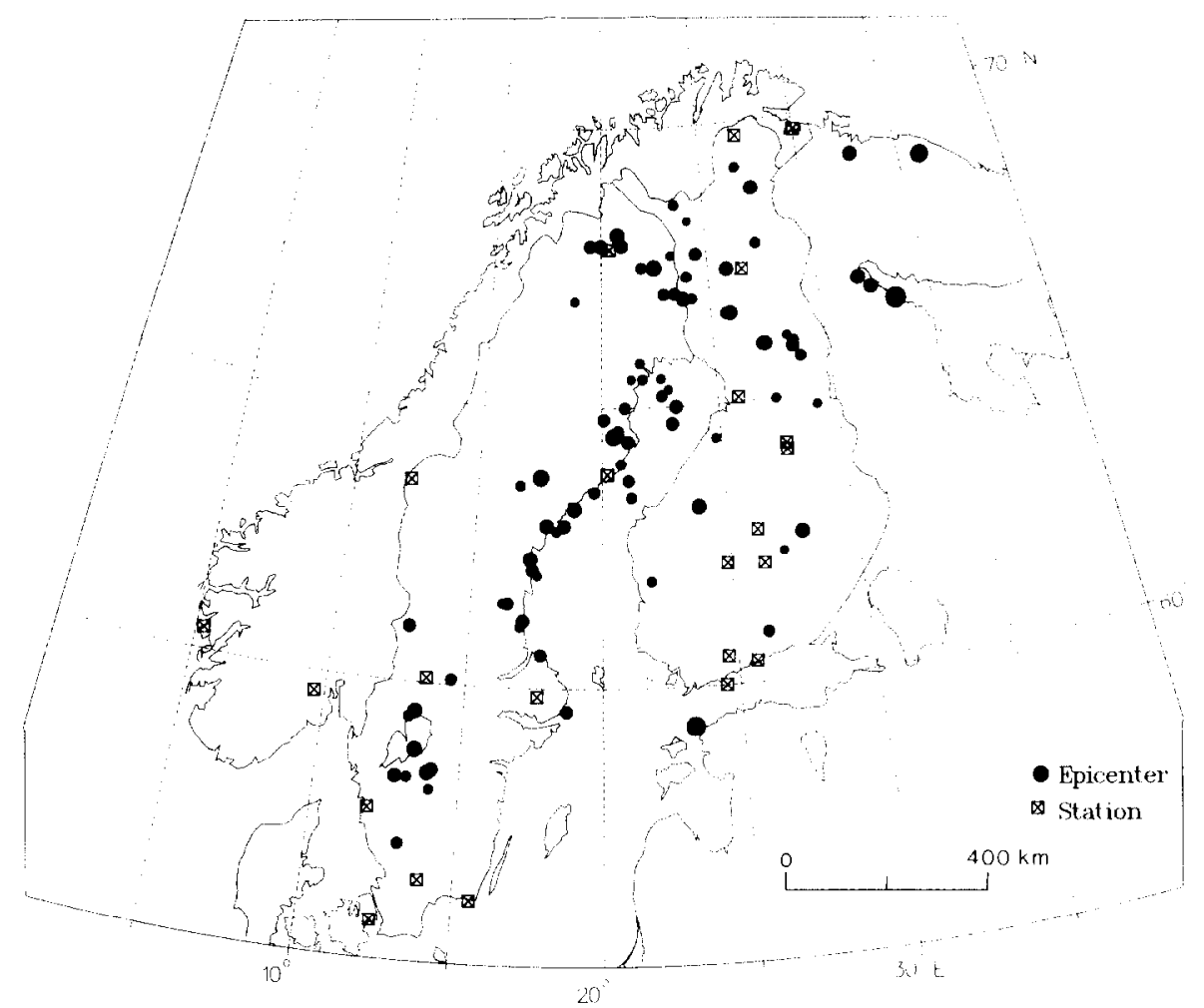

Fig. 1. Epicentral distribution of 90 earthquakes with magnitude $\left(M_{\mathrm{L}}\right) 2.0-5.2$ selected for spectral analysis and locations of 23 seismograph stations providing short-period, vertical-component $\mathbf{L g}$-wave records. The size of each dot is proportional to the magnitude. The inset dot corresponds to magnitude 4.

central distances are in the range of about $50-1500$ $\mathrm{km}$. We have made sure that no $\mathrm{Sn}$ waves pollute the $\mathrm{Lg}$ data used. Twelve stations have a WWSSN-equivalent Benioff seismometer, five Grenet $\left(T_{0}=1.4 \mathrm{~s}, T_{\mathrm{g}}=0.7 \mathrm{~s}\right)$, three Willmore Mark II $\left(T_{0}=0.8 \mathrm{~s}, T_{\mathrm{g}}=0.2 \mathrm{~s}\right)$ and three Geotech S-13 $\left(T_{0}=0.8 \mathrm{~s}\right)$. The use of analog seismograms imposes a limit on the highest frequency to be analysed to about $5-10 \mathrm{~Hz}$.

Selected seismograms were photographically enlarged five to ten times and the portions containing the $\mathrm{Lg}$ wave were electronically digitized. The digitized data were detrended for linear trend and interpolated for an equal-time interval of 0.05 $s$ using the piecewise continuous cubic polynomial (Wiggins, 1976). In many cases, records from the large events (magnitude usually greater than 3.5) at short distances cannot be used due to missing traces (oversaturation). Two typical digitized seismograms are shown in Fig. 2; a weak Lg trace with high level of background noise (Fig. 2a), and a strong $\mathrm{Lg}$ trace with low level of noise (Fig. 2b).

\section{Method of analysis}

The digitized seismograms were Fourier transformed to obtain trace amplitude spectra. The time window used for the spectral conversion varies from about 10 to $30 \mathrm{~s}$ depending upon the distance and size of each event. Observed Lg-wave amplitude spectra were then corrected for instrument response to obtain estimates of the ground displacement spectral density. To minimize the influence of the noise, the displacement spectra were considered only in a frequency band for which the instrument response is greater than one tenth of the peak magnification. This criterion delimits the available frequency range to about $0.3-8 \mathrm{~Hz}$ for most of the instruments used. In some cases, displacement spectra are reliable only up to about $5 \mathrm{~Hz}$. 

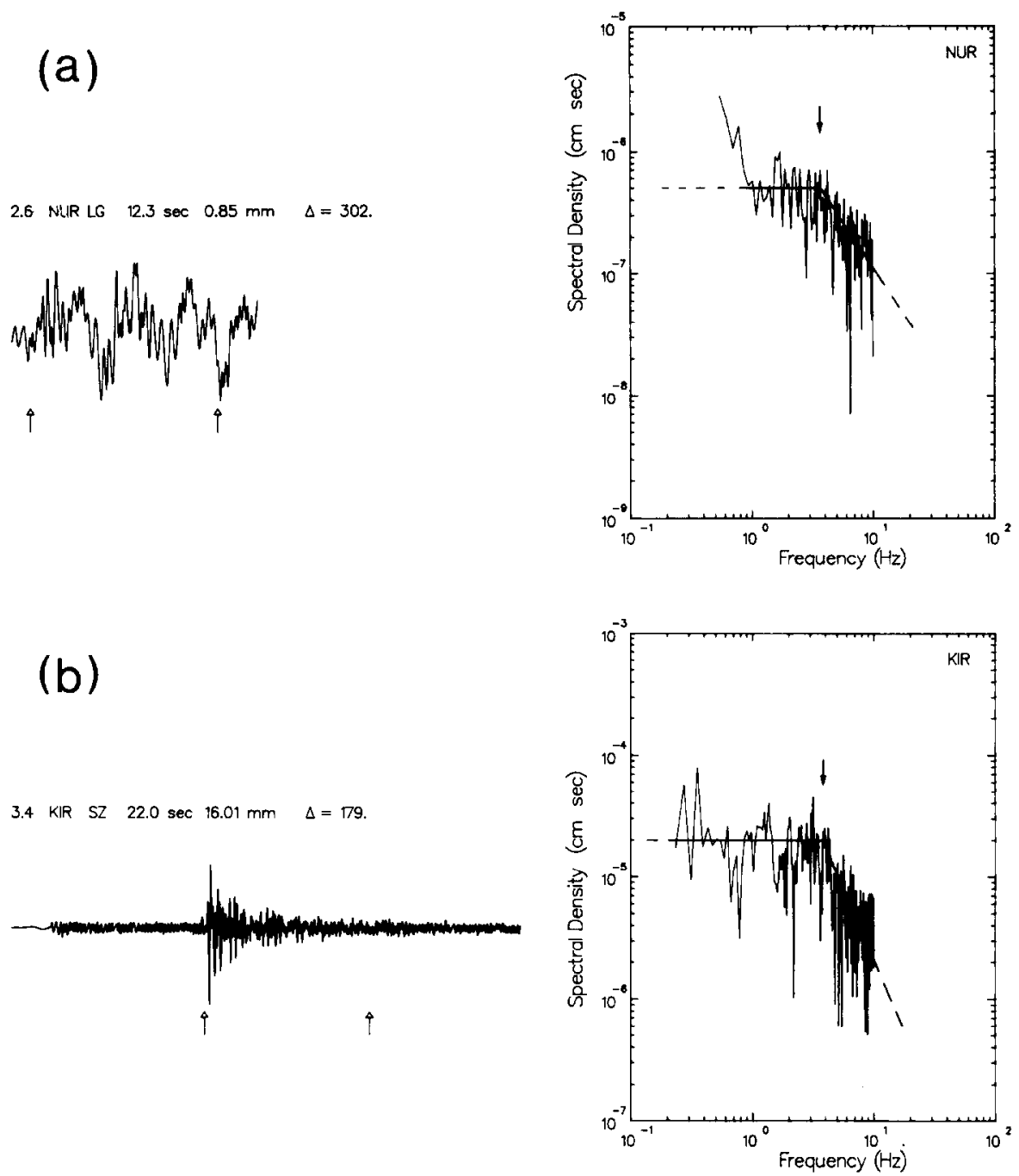

Fig. 2. Digitized seismograms and corresponding ground displacement amplitude spectra. a. 17 February $1979, M_{\mathrm{L}}=2.6$, recorded at Nurmijärvi (NUR) at a distance of $302 \mathrm{~km}$. The maximum peak-to-peak trace amplitude is $0.85 \mathrm{~mm}$. A time window of $12.3 \mathrm{~s}$ (between arrows) is used for the spectral conversion. b. 4 September 1968. $M_{\mathrm{L}}=3.4$, recorded at Kiruna (KIR) at a distance of 179 $\mathrm{km}$. The maximum peak-to-peak trace amplitude is $16.01 \mathrm{~mm}$. A time window of $22.0 \mathrm{~s}$ is used. Note that (a) and (b) are plotted with different time scales. In the spectra, selected low-frequency levels and high-frequency asymptotes (slope-2) are indicated by straight lines, and corner frequencies by arrows.

From displacement spectra, the constant lowfrequency spectral level $\left(\Omega_{0}\right)$ and the corner frequency $\left(f_{R}\right)$ were determined for each event and station. Examples of spectra and corresponding seismograms are shown in Fig. 2. For the plotted spectra, amplitudes at frequencies above $f_{R}$ fall off with increasing frequency, with a slope of about -2 .
3.1. Determination of low-frequency spectral level, $\Omega_{0}$

The effect of anelastic attenuation is not considered in determining $\Omega_{0}$ from the $\mathrm{Lg}$ spectrum, since it has insignificant effect upon the estimates of the spectral densities in the low-frequency band $(f \leqslant 1 \mathrm{~Hz})$ at which the $\Omega_{0}$ levels are set in most 
cases. The Lg-wave amplitude decrement due to anelastic attenuation is proportional to $\exp (-\gamma R)$, where $R$ is distance and $\gamma$ is the coefficient of anelastic attenuation, which, in its turn, is related to the quality factor, $Q$ (Nuttli, 1986):

$\gamma(f)=\pi f /[U(f) Q(f)]$

where $f$ is the wave frequency and $U$ the $\mathrm{Lg}$-wave group velocity. The reported value of $\gamma$ for $\mathrm{Lg}$ waves at $1 \mathrm{~Hz}$ in the central United States (Nuttli, 1973) and southeastern United States (Bollinger, 1979 ) is $0.0006 \mathrm{~km}^{-1}$. Chun et al. (1987) reported $\gamma(f)=0.0008 f^{0.81} \mathrm{~km}^{-1}$ for eastern Canada. According to these results, neglecting the effect of anelastic attenuation would introduce a maximum error of a factor of about three at a distance of $1000 \mathrm{~km}$ for the $1 \mathrm{~Hz}$ spectral component. Most of our observations were made at distances less than $1000 \mathrm{~km}$, in which cases the error would be even smaller. Note that $\Omega_{0}$ used in the $M_{0}$ computation (Section 4.1) is measured from the peak values of spectral densities at low frequencies. When $\Omega_{0}$ is measured from average values of the low-frequency level (as in Fig. 2), a multiplication factor of two has to be applied (Herrmann and Kijko, 1983).

\subsection{Determination of corner frequency, $f_{0}$}

The correction for the effect of anelastic attenuation upon the observed Lg-wave corner frequency is difficult to make, since the attenua- tion is not very well known for these waves in the range of observed frequencies (roughly $1-5 \mathrm{~Hz}$ ). Recent studies indicate that the quality factor, $Q$. for $\mathrm{Lg}$ waves depends upon the frequency and that the dependency is exponential (e.g., Singh and Herrmann, 1983):

$Q(f)=Q_{0} f^{\eta}$

where $Q_{0}$ is $Q$ at a reference frequency of $1 \mathrm{~Hz}$, and $\eta$ is a numerical constant. For the eastern United States, $Q_{0}$-values have been computed for several tectonically stable regions. Values of $Q_{0}$ vary between 460 and 900 , and $\eta$ between about 0.3 and 0.5 (Singh and Herrmann, 1983; Pulli, 1984; Gupta and McLauglin, 1987). For eastern Canada, $Q_{0}$ varies from about 500 to 1100 , and $\eta$ from about 0.2 to 0.65 (Hasegawa, 1985; Chun et al., 1987; Shin and Herrmann, 1987). If we take $Q_{0}=1100$ and $\eta=0.19$ (Chun et al., 1987), the 5 $\mathrm{Hz}$ spectral component would show an amplitude decrement of a factor of about four at a distance of $500 \mathrm{~km}$, and a factor of about 20 at a distance of $1000 \mathrm{~km}$. Hence, the effect of attenuation upon the high-frequency spectral component at large distances is significant. It is not quite clear whether the attenuation due to scattering is as important as the anelastic attenuation in this frequency band (see, e.g., Aki, 1980; Dainty, 1981).

In Fig. 3 the observed corner frequencies are plotted versus distance for two different magnitude ranges. The data indicate a decrease of the

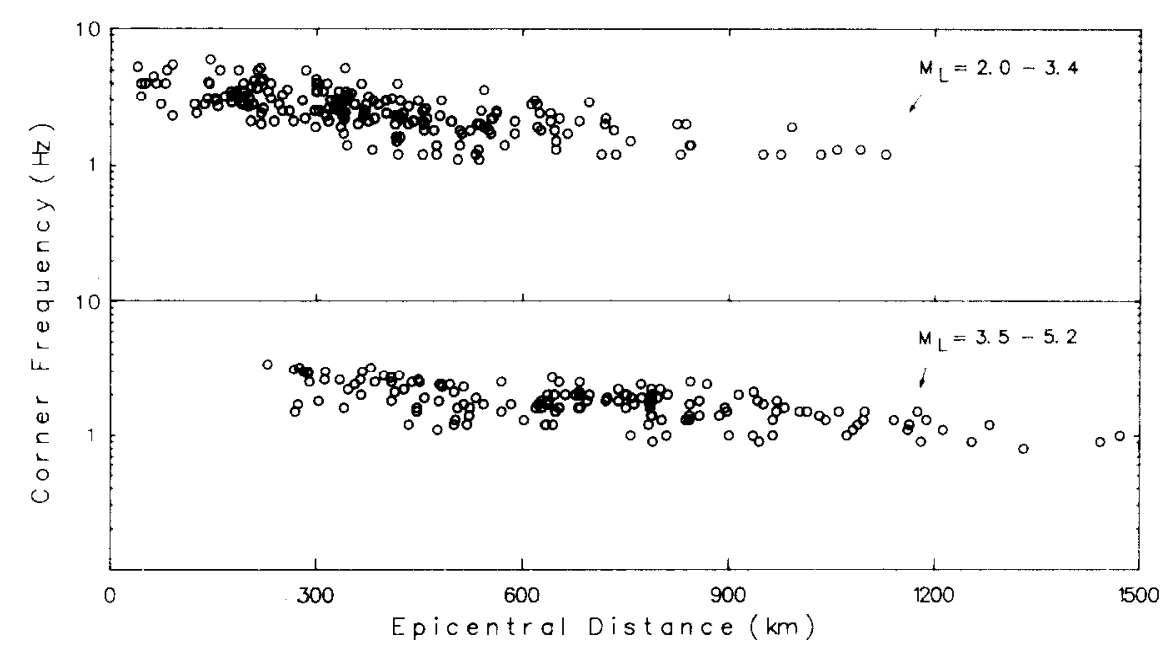

Fig. 3. Observed corner frequency $\left(f_{R}\right)$ plotted versus epicentral distance, for two groups of events selected on basis of magnitude $\left(M_{\mathrm{L}}\right)$. 
measured corner frequencies $\left(f_{R}\right)$ with increasing epicentral distance.

The events were then subdivided into four groups according to their seismic moment (Section 4.1). A linear regression was made between the corner frequency and distance for each group. Also, in these cases there is a decrease of corner frequency with increasing distance, and the decrease is smaller the larger the moment (Fig. 4). Hasegawa (1983) reports similar relationships for earthquakes in eastern Canada. The computed slopes were used to normalize the observed corner frequencies $\left(f_{R}\right)$ to zero distance. The normalized corner frequencies are averaged for each event, and the average $\left(f_{0}\right)$ is considered to be representative for the source-spectrum corner frequency. The source-spectrum corner frequencies for the events studied are listed in Table 1.

\section{Results}

\subsection{Seismic moment}

The seismic moment $\left(M_{0}\right)$ for the events studied is determined from the low-frequency spectral level $\left(\Omega_{0}\right)$ by applying the relation derived empirically by Street et al. (1975) and verified theoretically by Herrmann and Kijko (1983):

$$
M_{0}= \begin{cases}4 \pi \rho \beta^{3} R_{0}\left(R / R_{0}\right) \Omega_{0}, & R<R_{0} \\ 4 \pi \rho \beta^{3} R_{0}\left(R / R_{0}\right)^{1 / 2} \Omega_{0}, & R \geqslant R_{0}\end{cases}
$$

where $\rho$ is the density, $\beta$ is the shear wave velocity, $R$ is the epicentral distance, and $R_{0}$ is the reference distance. For the Baltic Shield earthquakes, we adopt the values $\rho=2.7 \mathrm{~g} / \mathrm{cm}^{3}, \beta=3.6$ $\mathrm{km} / \mathrm{s}$ and $R_{0}=100 \mathrm{~km} . R_{0}$ is used to account for different kinds of Lg-wave geometrical spreading:

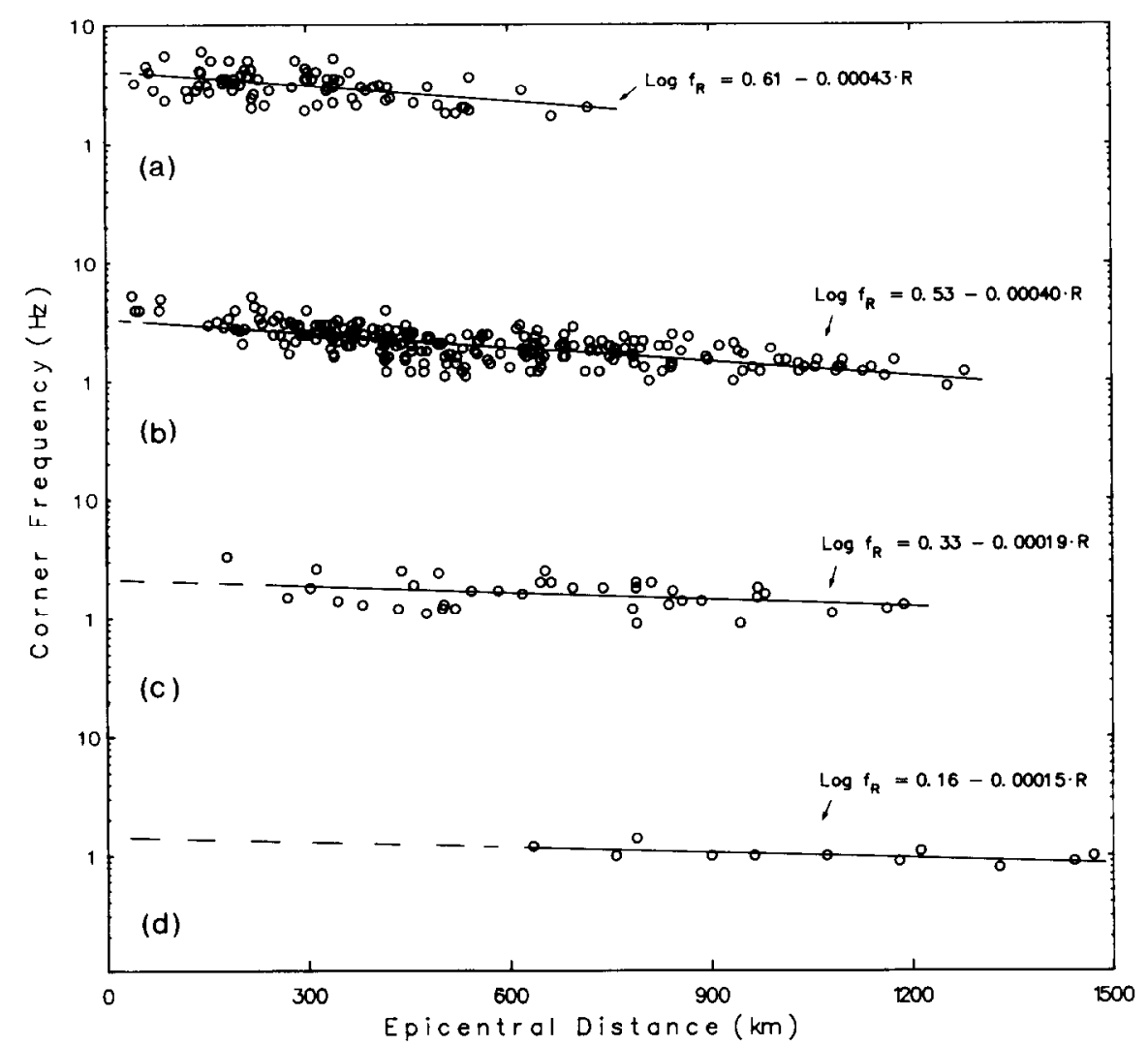

Fig. 4. Observed corner frequency plotted versus epicentral distance for four groups of events: seismic moment $\left(M_{0}\right.$, dyn $\left.\mathrm{cm}\right)$ less than (a) $5 \times 10^{19}$; (b) $5 \times 10^{19} \leqslant M_{0} \leqslant 5 \times 10^{20}$; (c) $5 \times 10^{20}<M_{0} \leqslant 5 \times 10^{21}$; (d) $M_{0}>5 \times 10^{21}$. 
At near distances ( $R<R_{0}$ ), the spreading is typically of the body-wave type (spherical), while at greater distances $\left(R>R_{0}\right.$ ), it is of the surface-wave type (cylindrical). The above formula is based on the relation of Keilis-Borok (1960) between the seismic moment and the far-field, low-frequency spectral level of $S$ waves: however, the source radiation pattern asymmetry is not considered in our interpretation. The Lg-wave train is composed of a family of rays undergoing subsequent multiple reflections and conversions as well as scattering within the crustal waveguide (see, e.g., Campillo et al., 1984; Kim, 1987). This makes the radiation pattern effect minor in the station record.

The seismic moment for each event is obtained as the average from all station readings. Estimates of the seismic moment for the events studied are listed in Table 1. It may be noted that the computed seismic moment for the second largest event, on 25 October $1976\left(M_{\mathrm{L}}=4.9\right)$, is in fair agreement with that of Slunga (1979), who obtained a value of $3-4 \times 10^{22}$ dyn $\mathrm{cm}$ using long-period surface waves.

\subsection{Source radius and stress drop}

Assuming the circular fault model of Brune (1970), the source radius $(r)$ can be estimated from the source-spectrum corner frequency $\left(f_{0}\right)$ through the relation:

$r=2.34 \beta /\left[2 \pi f_{0}\right]$

Calculated source radii range from 0.2 to $1.0 \mathrm{~km}$ (Fig. 5). The source radii for events with seismic moment less than $5 \times 10^{20}$ dyn $\mathrm{cm}$ increase only slightly with increasing moment, whereas the increase is larger for events with seismic moment above $5 \times 10^{20} \mathrm{dyn} \mathrm{cm}$. The source radii for the Meloy earthquake sequence in northern Norway reported by Bungum et al. (1982) also show very modest increase in the seismic moment range $10^{17}$ to $2 \times 10^{19}$ dyn cm (see Fig. 5).

The stress drop $(\Delta \sigma)$ is estimated from the relation (Keilis-Borok, 1959; Brune, 1970; Kanamori and Anderson, 1975):

$\Delta \boldsymbol{\sigma}=\frac{7}{16} M_{0} / r^{3}$

The estimates of the stress drop for most of the

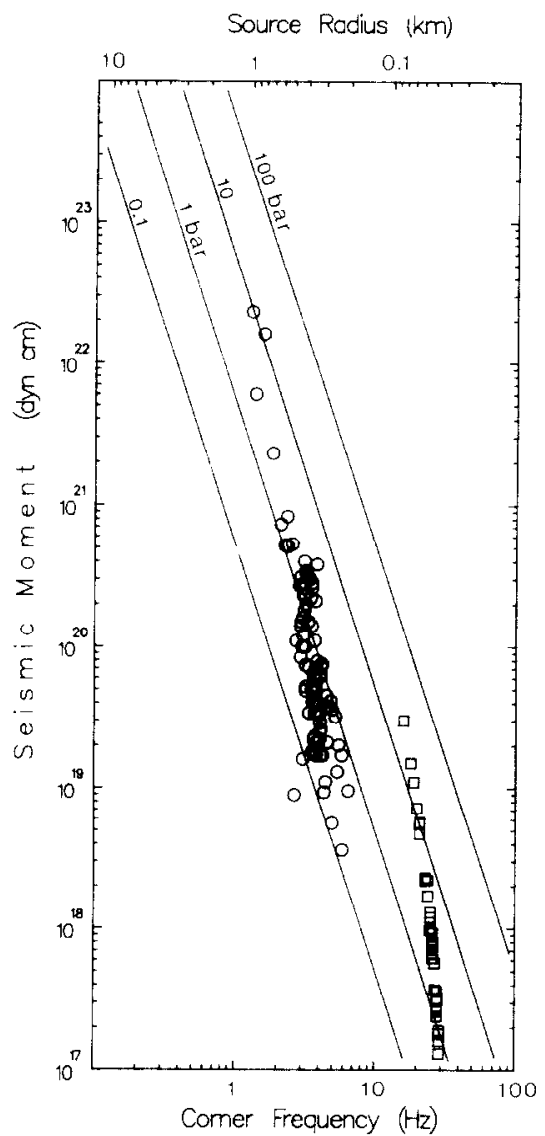

Fig. 5. Seismic moment plotted versus source-spectrum corner frequency and source radius (Brune, 1970 model). Circles indicate results from this study and squares results obtained by Bungum et al. (1982) for the Meloy aftershock sequence in northern Norway. Lines of constant stress drops of $0.1,1,10$ and 100 bar are indicated.

events fall between 0.1 and 10 bar. The stress drops are depicted in Fig. 5 using lines of constant stress drop, i.e. a slope of -3 for the seismic moment versus corner frequency relation.

The stress drops of the events studied are small compared with those of other regions and studies. They are one order smaller than those computed for earthquakes in eastern Canada with comparable moments (Hasegawa, 1983). The stress drops obtained by Bungum et al. (1982) from the Meloy sequence in northern Norway are 1-2 orders larger than ours (see Fig. 5). Small events in southern Sweden studied by Slunga et al. (1984, see their Fig. 6) in the moment range $10^{18}-10^{20} \mathrm{dyn} \mathrm{cm}$ also show at least one order larger stress drops than our results. Although Slunga et al. (1984) use 


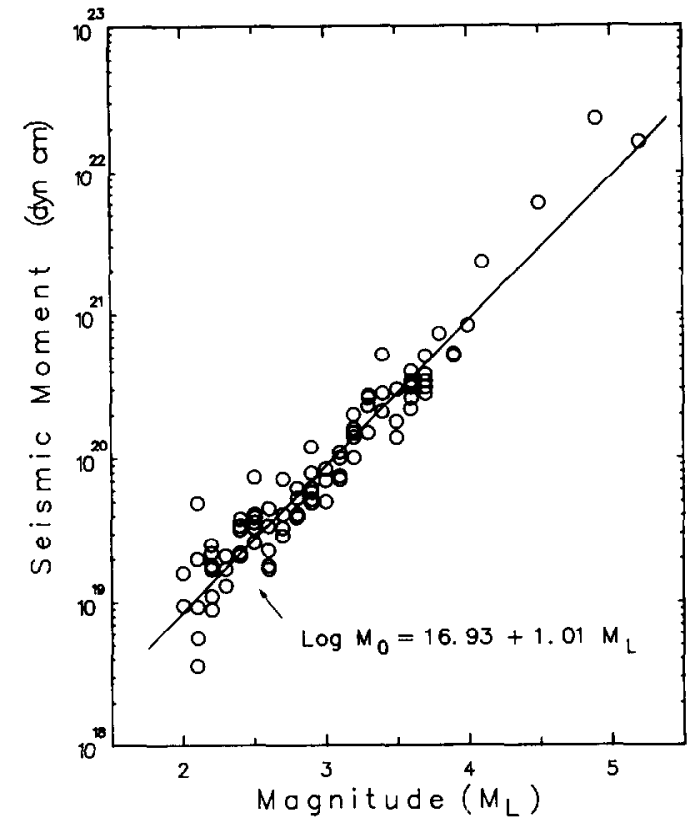

Fig. 6. Seismic moment plotted versus inagnitude $\left(M_{\mathrm{L}}\right)$.

a source model other than that of the present study, and Brune et al. (1986) suggest a possible existence of small low stress-drop events (partial stress-drop model of Brune, 1970) intermixed with high stress-drop events, it is difficult to explain our small values. Possibly the true corner frequencies, particularly for the smaller events, are close to or even larger than the upper limit of the reliable frequency range from the type of recording we use $(5-10 \mathrm{~Hz})$, so that our "observed" corner frequencies are too small. This implies an even larger decrease in stress drops (proportional to $f_{0}^{3}$ ). Note, however, that similar, low stress drops for earthquakes of corresponding size have been obtained in other studies, e.g., by Grosser et al. (1987) for the western Bohemia swarm in 1985-1986.

\subsection{Seismic moment - corner frequency relation}

The spectral-scaling relation between the seismic moment and the corner frequency has been derived for the moment range $3 \times 10^{18}$ to $3 \times 10^{22}$ dyn $\mathrm{cm}$ :

$\log f_{0}(\mathrm{~Hz})$

$$
=3.46( \pm 0.20)-0.15( \pm 0.01) \log M_{0}(\text { dyn } \mathrm{cm})
$$

However, by analogy to the source radius - moment relationship (Section 4.2), the corner frequency - moment dependency is different above and below about $5 \times 10^{20}$ dyn cm (see Fig. 5), but the slope of the moment-frequency relationship is steeper than -3 also for the larger events. A slope steeper than -3 has also been reported for the central United States (Street et al., 1975), northeastern North America (Street and Turcotte, 1977), and eastern Canada (Hasegawa, 1983).

\subsection{Seismic moment -magnitude relation}

Figure 6 shows the seismic moment plotted versus magnitude $\left(M_{\mathrm{L}}\right)$ for the earthquakes in our study. The empirical relationship between the moment, determined from Lg-wave amplitude spectra, and the magnitude $\left(M_{\mathrm{L}}\right)$ reads (Fig. 6):

$$
\begin{aligned}
& \log M_{0}(\mathrm{dyn} \mathrm{cm}) \\
& \quad=16.93( \pm 0.09)+1.01( \pm 0.03) M_{\mathrm{L}}, \\
& 2 \leqslant M_{\mathrm{L}} \leqslant 5.2
\end{aligned}
$$

A similar relationship is reported for earthquakes in southern Sweden with magnitudes between 1 and 3.3 (Slunga et al., 1984). The relationship is also comparable to that found for eastern Canada (Hasegawa, 1983), whereas for the western United States an equivalent local magnitude corresponds to a seismic moment one order larger (Wyss and Brune, 1968; Hanks and Boore, 1984). A change in the moment-magnitude relation at a seismic moment between $10^{21}$ and $10^{22} \mathrm{dyn} \mathrm{cm}$, suggested in several investigations (Street et al,, 1975; Hasegawa, 1983; Nuttli, 1983), could not be observed with confidence in this study due to the small numbers of large events.

\section{Discussion and conclusions}

The source radii for Baltic Shield earthquakes calculated from the corner frequencies are only slightly decreasing with increasing seismic moment in the range $3 \times 10^{18}$ to $5 \times 10^{20}$ dyn $\mathrm{cm}$ (Fig. 5). Although there are some uncertainties in the measured corner frequencies, possibly due to the analog data used, this weak dependence im- 
plies a strong increase of stress drop for increasing seismic moment (Fig. 5).

Nearly constant source radii over some moment range (usually for small events) is suggested in several recent studies employing high-quality digital data at short-distance ranges: e.g., Fletcher et al. (1986) for earthquakes near the Anza array, California; Archuleta (1986) for earthquakes with moment less than $10^{21}$ dyn $\mathrm{cm}$ in Mammoth Lakes, California; and Mueller and Cranswick (1985) (in their Fig. 7) for Miramichi, New Brunswick aftershocks.

The low stress drops obtained for small Baltic Shield earthquakes with seismic moment less than $10^{21}$ dyn $\mathrm{cm}$ may, at least partly, be caused by the analog data used.

The Baltic Shield earthquakes are characterized by a steadily increasing stress drop for increasing seismic moment, which is a consequence of the decrease of corner frequency with increasing seismic moment by a slope steeper than -3 (Fig. 5).

A constant stress-drop, source-scaling relation has been suggested by Kanamori and Anderson (1975) for large shallow earthquakes $\left(M_{0}>10^{25}\right.$ dyn $\mathrm{cm}$ ) and by Somerville et al. (1987) for earthquakes with $M_{0}>6 \times 10^{22}$ dyn $\mathrm{cm}$ in eastern North America and other intraplate regions. However, a slope steeper than -3 for the curve relating the corner frequency to the seismic moment implies that the similarity assumption proposed for the source-scaling law (Aki, 1967; Kanamori and Anderson, 1975) may not be valid for the small earthquakes considered in this study. Chouet et al. (1978) found such a departure from the similarity assumption for small earthquakes in various regions.

The linear relationship between seismic moment and magnitude is similar to those found for small-magnitude earthquakes in the southern Baltic Shield, and for earthquakes in the Canadian Shield.

\section{Acknowledgments}

This research has been carried out at the Seismological Department, Uppsala, with financial support from the Swedish Natural Science Re- search Council under contracts G-Gu 3164137 and 3164-141 (for W.Y.K.) and G-Gu 3164-143 (for R.W.), and the Swedish Nuclear Fuel and Waste Management Co. (for W.Y.K.). Assistance given by colleagues in Denmark, Finland and Norway in collecting seismogram data is greatly appreciated.

\section{References}

Aki, K., 1967. Scaling law of seismic spectrum. J. Geophys. Res., 72: 1217-1231.

Aki, K., 1980. Scattering and attenuation of shear waves in the lithosphere. J. Geophys. Res., 85: 6496-6504.

Archuleta, R.J., 1986. Downhole recordings of seismic radiation. In: S. Das, J. Boatwright and C.H. Scholz (Editors), Earthquake Source Mechanics. Geophys. Monogr., Am. Geophys. Union, 37: 319-329.

Bollinger, G.A., 1979. Attenuation of the $\mathrm{Lg}$ phase and the determination of $m_{\mathrm{b}}$ in the southcastern United States. Bull. Seismol. Soc. Am., 69: 45-63.

Brune, J.N., 1970. Tectonic stress and the spectra of seismic shear waves from earthquakes. J. Geophys. Res., 75: 4997-5009.

Brune, J.N., 1971. Correction to tectonic stress and the spectra of seismic shear waves from earthquakes. J. Geophys. Res., 76: 5002 .

Brune, J.N., Fletcher, J., Vernon. F.. Haar, L., Hanks, T. and Berger, J., 1986. Low stress-drop earthquakes in the light of new data from the Anza, California telemetered digital array. In: S. Das, J. Boatwright and C.H. Scholz (Editors), Earthquake Source Mechanics. Geophys. Monogr. Am. Geophys. Union, 37: 237-245.

Bungum, H., Vaage, S. and Husebye. E.S., 1982. The Meloy earthquake sequence, northern Norway: source parameters and their scaling relations. Bull. Seismol. Soc. Am., 72: 197-206

Campillo, M., Bouchon, M. and Massinon, B., 1984. Theoretical study of the excitation, spectral characteristics, and geometrical spreading of regional seismic phases. Bull. Seismol. Soc. Am., 74: 79-90.

Chouet, B., Aki, K. and Tsujiura, M.. 1978. Regional variation of the scaling law of earthquake source spectra. Bull. Seismol. Soc. Am., 68: 49-79.

Chun. K.-Y., West, G.F., Kokoski, R.J. and Samson, C., 1987. A novel technique for measuring $\mathrm{Lg}$ attenuation-results from eastern Canada between 1 to $10 \mathrm{~Hz}$. Bull. Seismol. Soc. Am., 77: 398-419.

Dainty, A.M., 1981. A scattering model to explain seismic $Q$ observations in the lithosphere between 1 and $30 \mathrm{~Hz}$. Geophys. Res. Lett., 8: 1126-1128.

Fletcher, J.B., Haar, L.C., Vernon, F.L., Brune, J.N., Hanks, T.C. and Berger, J., 1986. The effects of attenuation on the scaling of source parameters for earthquakes at Anza, California. In: S. Das, J. Boatwright and C.H. Scholz 
(Editors), Earthquake Source Mechanics. Geophys. Monogr., Am. Geophys. Union, 37: 331-338.

Grosser, H., Burghardt, P.Th. and Köhler, W., 1987. Spectral calculations and focal parameter studies of selected events of the west Bohemia earthquake swarm 1985/1986. In: Earthquake Swarm 1985/86 in Western Bohemia. Proc. of Workshop in Marianske Lazne, Czech. Acad. Sci., Geophys. Inst., Prague, pp. 282-292.

Gupta, I.N. and McLaughlin, K.L., 1987. Attenuation of ground motion in the eastern United States. Bull. Seismol. Soc. Am., 77: 366-383.

Hanks, T.C. and Boore, D.M., 1984. Moment-magnitude relations in theory and practice. J. Geophys. Res., 89: 6229-6235.

Hasegawa, H.S., 1983. Lg spectra of local earthquakes recorded by the Eastern Canada Telemetered Network and spectral scaling. Bull. Seismol. Soc. Am., 73: 10411061.

Hasegawa, H.S., 1985. Attenuation of $\mathrm{Lg}$ waves in the Canadian Shield. Bull. Seismol. Soc. Am., 75: 1569-1582.

Herrmann, R.B. and Kijko, A., 1983. Modeling some empirical vertical component $\mathrm{Lg}$ relations. Bull. Seismol. Soc. Am., 73: $157-171$.

Kanamori, H. and Anderson, D.L., 1975. Theoretical basis of some empirical relations in seismology. Bull. Seismol. Soc. Am., 65: 1073-1095.

Keilis-Borok, V., 1959. On estimation of the displacement in an earthquake source and of source dimensions. Ann. Geofis., 12: 205-214.

Keilis-Borok, V., 1960. Investigation of the mechanism of earthquakes. Sov. Res. Geophys., 4-American Geophysical Union, Consultants Bureau, New York, 201 pp.

Kim, W.Y., 1987. Modelling short-period crustal phases at regional distances for the seismic source parameter inversion. Phys. Earth Planet. Inter., 47: 159-178.

Kim, W.Y., Wahlström, R. and Ahjos, T., 1985. Source parameters of earthquakes in the Baltic Shield. Proc. 19th General Assembly, European Seismol. Commission., Moscow, Oct. 1984.

Kulhanek, O., Van Eck, T., John, N., Meyer, K. and Wahlström, R., 1983. Spectra of the earthquake sequence FebruaryMarch, 1981, in south-central Sweden. Tectonophysics, 93: $337-350$.
Mueller, C.S. and Cranswick, E., 1985. Source parameters from locally recorded aftershocks of the 9 January 1982 Miramichi, New Brunswick, earthquake. Bull. Seismol. Soc. Am., 75: 337-360.

Nuttli, O.W., 1973. Seismic wave attenuation and magnitude relations for eastern North America. J. Geophys. Res., 78: 876-885.

Nuttli, O.W., 1983. Average seismic source parameter relations for mid-plate earthquakes. Bull. Seismol. Soc. Am., 73: 519-535.

Nuttli, O.W., 1986. Yield estimates of Nevada Test Site explosions obtained from seismic $\operatorname{Lg}$ waves. J. Geophys. Res., 91: 2137-2151.

Pulli, J.J., 1984. Attenuation of coda waves in New England. Bull. Seismol. Soc. Am., 74: 1149-1166.

Shin, T.-C. and Herrmann, R.B., 1987. Lg attenuation and source studies using 1982 Miramichi data. Bull. Seismol. Soc. Am., 77: 384-397.

Singh, S. and Herrmann, R.B., 1983. Regionalization of crustal coda $Q$ in the continental United States. J. Geophys. Res., 88: $527-538$

Slunga, R., 1979. Source mechanism of a Baltic earthquake inferred from surface-wave recordings. Bull. Seismol. Soc. Am., 69: 1931-1964.

Slunga, R., Norrman, P. and Glans, A., 1984. Baltic shield seismicity, the results of a regional network. Geophys. Res. Lett., 11: 1247-1250.

Somerville, P.G., McLaren, J.P., LeFevre, L.V., Burger, R.W. and Helmberger, D.V., 1987. Comparison of source scaling relations of eastern and western North American earthquakes. Bull. Seismol. Soc. Am., 77: 322-346.

Street, R.L. and Turcotte, F.T., 1977. A study of northeastern North American spectral moments, magnitudes, and intensities, Bull. Seismol. Soc. Am., 67: 599-614.

Street, R.L., Herrmann, R.B. and Nuttli, O.W., 1975. Spectral characteristics of the $\mathrm{Lg}$ wave generated by central United States earthquakes. Geophys. J.R. Astron. Soc., 41: 51-63.

Wiggins, R.A., 1976. Interpolation of digitized curves. Bull. Seismol. Soc. Am., 66: 2077-2081.

Wyss, M. and Brune, J.N., 1968. Seismic moment, stress, and source dimensions for earthquakes in the CaliforniaNevada region. J. Geophys. Res., 73: 4681-4694. 